\title{
Information Usefulness and Attitude Formation a Double-Dependent Variable Model (DDV) to Examine the Impacts of Online Reviews on Consumers
}

\author{
Jinting Lu, School of Journalism and Communication, Xiamen University, Xiamen, China \\ Haiqing Bai, School of Journalism and Communication, Xiamen University, Xiamen, China
}

\begin{abstract}
With the popularity of online shopping, a large body of studies have paid much attention to the factors influencing consumer information seeking and assessing. However, theoretical development and empirical testing are still not enough to explain this phenomenon; that is, during the information seeking and assessing process, what factors play a decisive role is a question needed to be deeply explored? This study, thus, aim to understand the impact of the attributes of online reviews on consumer. In addition, the authors find that review volume (RV: a heuristic factor) has a direct impact on perceived usefulness (PU) and attitudes (ATT), while source credibility (SC: another heuristic factor) only influences the perceived usefulness (PU) but has no effect on attitudes (ATT). As for the moderating effects, perceived social-psychological risk (PSR) moderates the effects of both review volume (RV) and source credibility (SC) on perceived usefulness and attitudes. The authors explore the reasons underlying those findings and also discuss implications for both researchers and practitioners.
\end{abstract}

\section{KEYWORDS}

Attitudes, DDV Mode, Online Reviews, Perceived Social-Psychological Risk, Perceived Usefulness

\section{INTRODUCTION (OR MOTIVATION FOR THE STUDY)}

With the popularity of online shopping, information seeking plays an important role in the online purchase decision-making process (Hussain et al., 2018; Luo, Luo, \& Bose, 2018; C.-C. Teng, Lu, $\&$ Huang, 2018). Online reviews form a critical and unavoidable facet of e-commerce, these reviews have a significant impact on consumers purchase decisions as well as the amount of money spent by consumers (Wu, Ngai, Wu, \& Wu, 2020). Many studies have paid much attention to consumers' response to online reviews, few researches pay attention to an integrated effect of characteristics of reviews and consumers. Thus, drawing on the dual of process theory (DPT), this study investigated the influence of online reviews from three aspects: information source, information itself and information receiver. Specifically, content and review picture represent information source, while we choose four attributes of online reviews confirmed by other studies: content quality and picture quality, review volume and source credibility, to see how they affect consumers' perceived usefulness and attitudes. Furthermore, the usefulness of online reviews also depends on information receiver who are seeking 
useful information. In this study, perception of social-psychological risks is viewed as a comprehensive index representing the characteristics of information receiver.

To sum, this study adopts a comprehensive approach and theories to analyze the online reviews' effects on consumer, proposes and empirically tests a comprehensive double dependent variable-DDV model, and presents some managerial and theoretical implications.

\section{THEORETICAL BACKGROUND}

\subsection{WOM, eWOM, Online Reviews and the Travel Industry}

Word of mouth (WOM) is an important concept in marketing and communication, it refers to informal interpersonal communication between the sender and the receiver about the enterprise, product, brand, organization or service they are concerned about ((Arndt, 1967). Much research in the field of management has focused on the impact of word of mouth on marketing (Chatterjee, 2001; C. M. K. Cheung, Lee, \& Rabjohn, 2008; Eslami \& Ghasemaghaei, 2018; Ghosh, 2018; Hansen, Jensen, \& Solgaard, 2004; Litvin, Goldsmith, \& Pan, 2008; Sher \& Lee, 2009). In this aspect, the definition of word of mouth can be summarized as a market information exchange behavior between consumers, which plays an important role in changing consumer attitudes and behaviors.

Traditional WOM has proven to be a powerful influence on consumer decisions. As Internet could improve the speed of communication, the way of word-of-mouth changed. In view of the characteristics of Internet communication, scholars and managers attach great importance to the importance of Internet word of mouth. Westbrook (1987) defined eWOM communication as "informed communications directed at other consumers about the ownership, usage, or characteristics of particular goods and services and/or their sellers". eWOM spreads through a variety of different channels, such as email, BBS, instant messaging devices, personal pages, blogs, product review sites, virtual communities, chat rooms, and social networking sites. The anonymous and interactive nature of the Internet enables consumers to freely share or search for experiences related to products, influencing their brand choice and sales of goods and services.

Consumers often encounter such situations: that is, when the shopping network is unable to get access to the products they want to buy, or feel that the information provided by the website is not complete, consumers are more inclined to check online reviews to reduce their sense of uncertainty (Zhang, Zhao, Cheung, \& Lee, 2014). Manganari and Dimara (2017) found that online travel reviews can influence consumers' booking intention, positive reviews result in more positive and higher booking intention, and the presence of emoticons in negative reviews strengthens the review credibility and usefulness, but attenuates consumers' attitudes towards the hotel and their booking intention. While these reviews provide travelers with information, they also create a reputation management situation for travel websites (Chen \& Chang, 2018). This phenomenon has led researchers and marketers to investigate the true impact of reviews. Most relevant to this research are studies regarding peripheral cues (Aghakhani, Karimi, \& Salehan, 2018; Filieri, Hofacker, \& Alguezaui, 2018; Risselada, de Vries, \& Verstappen, 2018) and content characteristics (Huang, Li, Wu, \& Lin, 2018; Kim, Maslowska, \& Malthouse, 2018). Agag and El-Masry (2016) examines the antecedents of customers' intention to participate in online travel community. Book, Tanford, and Chang (2018) suggests that online customer reviews and ratings are powerful sources of information that influence travel purchase intentions, and indicates that ambiguous base rate information and high processing effort cause consumers to pay greater attention to review content, in turn, this influences consumers' perceptions, decisions, and recall. All those studies confirmed that consumers' heavy reliance on online reviews before they go out for a planned travel. Then, from the reviewers' credibility, website characteristic (content in the online reviews), to consumer themselves(their information process and risk preference), are 3 main interaction aspects to be discussed in this study, also it is the reason why 
we choose information perceived usefulness and attitudes as two dependent variables in this study, which was significantly different from prior studies..

\subsection{Dual-Process Theory, Attributes of Review, Perceived Usefulness and Attitude}

When consumers are in the face of numerous online reviews, they may use different information processing model to assess the validity of received information. In prior literature, dual-process theories have been commonly applied to examine the role played by both the information content of the message and the factors of its context affecting message credibility. Heuristic-systematic model (HSM) and elaboration likelihood model (ELM) are two most prominent theories that use the dual process approach(Baek, Ahn, \& Choi, 2012). These theories have been most influential in the field of persuasion and attitude change(Smith. \& DeCoster, 2000), they are composed of content-related characteristics (e.g. argument quality) and non-content cues (e.g., source credibility) of presented messages in websites. To this day, more studies adopted ELM to test their hypotheses(Filieri et al., 2018; Hussain, Ahmed, Jafar, Rabnawaz, \& Yang, 2017; Luo, Luo, Xu, Warkentin, \& Sia, 2015), fewer studies applied heuristic-systematic model to explain relationship between online reviews and consumer behavior intention(Chang, Fang, \& Huang, 2015; Zhang et al., 2014).

According to HSM, people (receivers) assess the validity of received content during information acquisition, via two information processing modes - systematic processing and heuristic processing. During systematic processing, a receiver scrutinizes the presented information carefully. During heuristic processing, a receiver adopts heuristics and simple decision rules embedded in the message context to do this. As heuristic-systematic model (HSM) highlights the influence of both the information content of a received message and receivers, applying to our study, we adopt HSM to analyze reader's attempt to comprehend and evaluate the arguments in the message, assess their validity in relation to the conclusion. However, the effectiveness of those two processing depends on the quality of information itself and receiver. For example, systematic processing requires readability of message (e.g., argument quality), and receivers' motivation and enough cognitive resources. Likewise, heuristic processing depends on the cues' credibility.

Based on WOM and HSM, this study builds a research model with aim to investigate interaction effects of characteristics of reviews and reviewers (potential consumers) on the perceived usefulness of consumers in travel websites. Specially speaking, characteristics of reviews, i.e. systematic and heuristic factors in this study include picture, content, review volume, and source credibility. Besides, when people are awash in information, the social-psychological risk of potential consumers is viewed as a comprehensive index reflecting reviewers' characteristics. Moreover, we firstly took perceived usefulness and attitudes as outcome variables, as a large body of former studies have proved that there are causal relationships between perceived usefulness, attitudes, and their subsequent behavioral intention (Amaro \& Duarte, 2015; Elwalda, Lue, \& Ali, 2016; Erkan \& Evans, 2016; Ghosh, 2018).

\subsubsection{Review Quality (CQ, PQ) and Perceived Usefulness, Attitudes}

While intangible experienced-based goods especially depend on online reviews (Furner \& Zinko, 2017), Existing studies have adopted various techniques in terms of the measurement of online review contents to understand potential customers' cognitive perceptions from online reviews (Cheng, Fu et al., 2019). Scholars have paid much attention to review quality, and review quality i.e. argument quality is defined as the impressive strength of a comment in an informational message and is considered an important aspect in modulating consumer evaluation of a message (Hussain et al., 2018). Moreover, concerning that product comments are written by online strangers, users are keen to explore a product's credibility and decide about the product. Product comments that are relevant and verified tend to be more convincing and are predicted as more trustworthy than those that are spacious (Hussain et al., 2018). D.-H. Park, Lee, and Han (2007) suggested that a high-quality review is one that is more logical and persuasive, and supports its evaluation with reasons based on the facts about a product. Also, a strong review quality message reflects the attitudes of the reviewer clearly, and contains how 




and why the reviewer has formed the particular attitudes toward the target (Shin, Van Der Heide, Beyea, Dai, \& Prchal, 2017). Other relevant studies also confirmed that information quality has an impact on user satisfaction, thereby affecting consumers' purchase intention (Amaro \& Duarte, 2015; Chang et al., 2015; Chen \& Chang, 2018; Hur, Kim, Karatepe, \& Lee, 2017; Kim et al., 2018; Luo et al., 2018; J. Park \& Hill, 2018; Sijoria, Mukherjee, \& Datta, 2018). However, when talking about online reviews, most studies actually refer to the content of reviews(S. Teng, Khong, Chong, \& Lin, 2017), hardly any studies differentiate reviews as text and picture, since modern e-commerce websites allow users to post pictures or photos about the product they bought. Chen and Chang (2018) suggest that review quality, or information quality (argument quality) refers to the accuracy, completeness, clarity, comprehensibility, usefulness, and reliability of information system data outputs. Hence, in response to Chen and Chang (2018)'s argument quality definition and in order to confirm the effects of text and picture of a review respectively, we divide review quality into content quality and picture quality, content review refers to the text content of the product purchase or use experience written by the reviewer. Namely, picture review refers to the photos or pictures taken by the reviewer to comprehensively display of the appearance or use of the product, such as the internal and external living environment of the hotel booked online.

There are scarce studies on the pictures in reviews. I. Lee (2018) studied the existence of image/ photos in a social shopper's review's influence on a viewer's perceived value of online reviews. The reviewer's picture may draw greater attention to the reviews. As most product reviews are brief and easy to understand, and are thus unlikely to demand a high level of cognitive resources for processing. Instead, the vivid visual cue may arouse greater interest in the associated review and motivate otherwise uninterested consumers to read more closely (E.-J. Lee \& Shin, 2014). For online travel consumers, they want to know whether the hotel or its environment is the same product as they expect, they may take picture a systematic factor to inference the usefulness of the review. Considering that heuristic 
cues exert less influence on subsequent judgments when message elaboration is high(Petty 1984), the reviewer's photo will facilitate message elaboration, thereby amplifying the effects of review quality(E.-J. Lee \& Shin, 2014).

Then we draw our hypothesis as below:

H1: Picture quality positively influences the review content quality.

H2: Content quality positively influences consumer perceived usefulness.

H3: Content quality positively influences consumer attitudes.

\subsubsection{Review Volume, and Perceived Usefulness, Attitudes}

Online review quantity (online review volume, review numbers) referred to the volume of online reviews available posted by reviewers to express their opinions(S. Teng et al., 2017). It is an important construct as the volume of online reviews leads to greater awareness and confidence levels by consumers(S. Teng et al., 2017). In the context of eWOM communication, if the number of online reviews increases, it is more likely that purchase intentions are enhanced because more and more consumers start to rationalize their decisions based on increased online review quantity. Consumers often infer that a product is popular if there are more positive online reviews than few reviews. Previous studies have discussed that online review quantity served as an important cue for product popularity and increased sales(Agag \& El-Masry, 2016; Hussain et al., 2016; I. Lee, 2018; X. Yan, Wang, \& Chau, 2015). X. Yan et al. (2015)studied the impact of online reviews quantity on customer revisit intention, S. Teng et al. (2017) found that review quantity is associated with consumers' attitudes toward products. The current volume of online reviews affects many consumers' purchase behavior, (Shen, Zhang, \& Zhao, 2016). In general, the consumers tend to believe that the products with a larger number of online reviews are more popular than those with fewer reviews. That's to say, increasing the number of reviews in a message might enhance persuasion by invoking a simple decision rule, "the more the better". Thus, we proposed:

H4: The review volume positively influences consumer perceived usefulness.

H5: The review volume positively influences consumer attitudes.

\subsubsection{Source Credibility, and Perceived Usefulness, Attitudes}

"Source credibility" is a term commonly used to imply a communicator's positive characteristics that affect the receiver's acceptance of a message(Ohanian, 1990). Source credibility is based on trustworthiness, attractiveness and expertise of the communicator (Ohanian,1990). Source credibility is the extent to which the target audience views the source in order to gain expertise and knowledge in their understanding of the product/service (Hussain et al., 2018; Kim et al., 2018; Ohanian, 1990). Several researchers have demonstrated the importance of source credibility, Kim et al. (2018) argue that source credibility is an important element of persuasion and the main determinant in consumers' decision-making. S. Teng et al. (2017) identified that review credibility is associated with consumers' attitudes toward products, which in turn affects consumers' purchase intentions. Information credibility is considered a crucial driver of the peripheral routes due to the fact that it is the message receivers' perception on the credibility of a message (Yusuf, Hussin, \& Busalim, 2018). Sijoria et al. (2018) argued that the persuasiveness of a message is enhanced by credible sources and immediate attitudes changes are induced when message recipients perceived information as credible. If a message reader perceived online reviews as low credibility, he or she would resist the persuasive intent of online reviews. Hence, consumers' judgment on message credibility determines the levels of information acceptance and its perceived usefulness. Kim et al. (2018) argued that online consumers' messages were more credible and persuasive than sellers' posted reviews because these reviews contained personal experience with products. Conversely, people tend not to accept messages if they considered 
online reviews as incredible and biased. S. Lee and Choeh (2016) found that reviewer identity has a greater influence on the helpfulness for experience goods. Applied to this study, under a planned travel behavior and the experiential nature of travel products, according to ELM, source credibility is a peripheral cue for people to perceive the usefulness of online reviews, hence, we posit that source credibility does not directly consumers' purchase intentions, but could influence their perceived usefulness of online reviews. Consequently, we suggest that:

H6: Source credibility positively influences consumer perceived usefulness.

H7: Source credibility positively influences consumer attitudes.

\subsection{The Moderating Role of Perceived Social-Psychological Risk}

Although online shopping is set with numerous advantages, risks also exist. Relevant research shows that perceived risk is a multi-dimensional concept, and consumers will perceive the risk if they realize that a specific purchase may not meet their purchase objectives. Relevant research proposes specific dimensions of perceived risk, which are different due to different characteristics of products or services. Perceived risk as defined by Rich (1964) that "the nature and amount of risk perceived by a consumer in contemplating a particular purchase decision". The amount of risk perceived by the consumer is a function of two general factors- the amount at stake in the purchase decision, and the individual feeling of subjective certainty that she will "win" or "lose" all or some of the amount at stake(Rich, 1964). As we are concerned with the characteristics of consumers, we put more emphasis on the latter general risk factor, that is, the individual feeling of subjective perceived social risk and psychological risk as social-psychological risk to validity consumers' characteristics while shopping travel online. According to Feathermana. and Pavloub. (2003), perceived social risk refers to potential loss of status in one's social group as a result of adopting a product or service, looking foolish or untrendy. Likewise, perceived psychological risk means that the selection or performance of the producer will have a negative effect on the consumer's peace of mind or self-perception(Mitchell, 1992), it is also refers to potential loss of self-esteem (ego loss) from the frustration of not achieving a buying goal(Feathermana. \& Pavloub., 2003).

Taylor (1974) argued that any choice situation always involves two aspects of risk: uncertainty about the outcome and uncertainty about the consequences. Uncertainty about the outcome can be reduced by acquiring and "handling" information. Uncertainty about the consequences can be dealt with by reducing the consequences through reducing the amount at stake or putting off the choice. In a choice situation, once perceived risk has been identified, there seems to be some reasonable evidence that subsequent consumer behavior can be determined in accordance with such risk(Taylor, 1974). And the amount at stake in a buying situation is determined by the importance of the buying goals, i.e., the value attached to attaining some set of goals(Rich, 1964). Feathermana. and Pavloub. (2003) suggested that perceived risk is commonly thought of as felt uncertainty regarding possible negative consequences of using a product or service

Considering that tourism products are experiential, that is, they cannot be judged before use, this kind of hedonic feature prompts people to search online information about tourism products and services, as online tourism reviews to help them buy or book tourism products(Baek et al., 2012). Blomberg-Nygard, Anderson, and United Nations World Tourism Org (2016) found that before making an online hotel reservation, consumers visit on average almost 14 different travel-related sites, with about 3 visits per site, and carry out 9 travel-related searches on search engines. Santosh, Babu, and Ieee (2014) pointed out that nearly half of consumers indicated that they would actively read or make relevant comments after using online products and services. In a planned purchase travel situation, people process information either in the systematic routes or in the heuristic route, though they are faced with more social and psychological risks originated from their personality and characteristics. They try their best to seek a balance between benefits and risks about the product, especially those 
experienced users targeted by this study. In other words, under a high motivated travel circumstance, people's perceived social-psychological risk, self-control level, motivation is different. Hence, we propose that social-psychological risk moderates the effects of online reviews on their perceived usefulness and attitude. Then we propose the following hypothesizes:

H8: The effect of review quality on perceived usefulness will be moderated with the increase of their perceived social-psychological risk.

H9: The effect of review volume on perceived usefulness will be moderated with the increase of their perceived social-psychological risk.

H10: The effect of source credibility on perceived usefulness will be moderated with the increase of their perceived social-psychological risk.

H11: The effect of review quality on attitudes will be moderated with the increase of their perceived social-psychological risk.

H12: The effect of review volume on attitudes will be moderated with the increase of their perceived social-psychological risk.

H13: The effect of source credibility on attitudes will be moderated with the increase of their perceived social-psychological risk.

\section{METHODOLOGY}

\subsection{Measurement Development and Questionnaire}

This study tries to test the hypotheses of relationship among dependent $\&$ independent variables, such as content quality, picture quality, review volume, source credibility, perceived social-psychological risk, perceived usefulness and attitude. To fulfill the study's aim, a measurement scale was adopted and modified to the context of this study. See Appendex 1 of each construct in detail. All measurements were based on a 5-point Likert scale ( $1=$ Strongly Disagree; 5=Strongly Agree). What's more, Cronbach alpha was used to test the reliability through SPSS24, confirmatory factor analysis (CFA) as proposed by M. Park and Lennon (2009) was used to measure the validity. Besides, structural equation modeling (SEM) was also used to check the model fitness, so that AMOS 24 software was applied for this purpose(See Fig.1).

\subsection{Data Collection}

To collect the data, the questionnaire was distributed online using Wenjuanxing (https://www.wjx. $\mathrm{cn} /$ ). In Early March of 2019, links to the survey were placed on Wechat and QQ. Throughout the whole month of March 2019, from March $1^{\text {st }}$ to March $31^{\text {st }}$, we conducted the data collection, finally got 1002 samples in total. Only 402 respondents passed the manipulation check, 47 were eliminated because the time used to fill out the questionnaire was too short. Thus, a total of 355 responses was considered valid for further analyses. See Appendix B.

\section{DATA ANALYSIS AND RESULTS}

\subsection{Descriptive Statistics}

The demographic characteristics of the respondents were displayed in Appendix B. Female respondents (53.5\%) were slightly more than their male counterparts $(46.5 \%)$. The respondents were fairly distributed across the different age groups with the clear majority between 19 and 45 . Most of the respondents had a bachelor degree or a higher qualification. The subjects' occupations were student, Company employer, Individual household/Self-employed, Civil servant, Sales/Services, and so on. About one third of them booked travel products for at least 1 time, more than $25 \%$ of them have booked travel products for more than 4 times. Most of the respondents was a user of certain travel 
website more than one year. As expected, all of them read online travel product reviews before they make decisions.

\subsection{Measurement Model}

The research model was tested using AMOS 24.0, a structural modeling technique which is well suited for predictive models (Bentler \& Bonett, 1980). We firstly used SPSS to analyze the reliability and validity of the scales. Convergent validity, which was examined by using the composite reliability (CR) and the average variance extracted (AVE), demonstrates how the items are related to each other; and to see if they are belonged to the same measurement or not. The lower acceptable value is 0.70 for CR and 0.5 for AVE (Fornell \& Larcker, 1981). As presented in Table 1, CR of each variable are more than 0.8 (0.818-0.968), and AVE of each variable are more than $0.50(0.556-0.834)$, which means the convergent validity is achieved. According to Hair, Black, Babin, and Anderson (2010), the recommended level for the factor loadings should be 0.50 or higher, ideally 0.70 or higher. We can see that most of the factor loadings of this study are greater than 0.70 , only 2 are below 0.70 , but above 0.50. All the factor loadings in Table 1 meet the standards.

Additionally, discriminant validity was analyzed in order to examine whether a measurement is not a reflection of any other measurement or not. In this analysis, each of the square roots of AVE should be higher than the other correlation coefficients for adequate discriminant validity(Fornell \& Larcker, 1981). As presented in Table 2, the square root of AVE for each variable is greater than the other correlation coefficients which indicate the discriminant validity is achieved.

\subsection{Model Fit and Hypothesis Testing}

Structural equation modelling (SEM) using AMOS 24.0.0 was employed to assess the hypothesized theoretical model. Firstly, the structural model fit was evaluated. Chi-square results $\left(\chi^{2}(265 \mathrm{df})\right.$ $=748.145)(\mathrm{p}<0.0001)$ suggest that the model fit is unsatisfactory. Chi-square statistics, however, are very sensitive to the sample size(Hair et al., 2010); therefore, it is an inadequate index in this study to reject the model. Thus, the following statistics were selected to determine the structural model's fit: Goodness-of-Fit Index (GFI), Adjusted Goodness-of-Fit Index (AGFI), Normed Fit Index (NFI), Tucker Lewis Index (TLI), Comparative Fit Index (CFI), Root Mean Square Error of Approximation (RMSEA), and Root Means Square Residual (RMR)(Hair et al., 2010). GFI, CFI, NFI, AGFI and TLI values of between 0.8 and 0.89 are considered to be a reasonable fit, while values between 0.9 and 1.0 are considered to be a good fit. RMSEA values less than 0.05 are considered to be a good fit, and values between 0.06 and 0.08 are considered as an acceptable fit. RMR values of less than 0.08 are preferred(Hair et al., 2010). Indices results show that GFI $=0.851$ AGFI $=0.817, \mathrm{CFI}=0.922$, $\mathrm{NFI}=0.884$, TLI $=0.911, \mathrm{RMSEA}=0.072$, and RMR $=0.054$, which suggests that the model fit is acceptable (Hair et al., 2010). Model fit indices are presented in Table 3.

The results of the DDV model are presented in Figure 2. As expected in H1, the picture quality has a positive significant effect on content quality, suggesting that pictures in the review is useful for people to infer and validate the content of reviews. The findings also support $\mathrm{H} 2$, indicating that review content significantly impacts customers' perceived usefulness of reviews. Moreover, review volume also has a significant influence on customers' perceived usefulness of reviews, source credibility has a significant impact on perceived usefulness of reviews too; hence, supporting $\mathrm{H} 3$ and $\mathrm{H} 4$. $\mathrm{H} 5$ regards that the content quality, which is influenced by picture quality, has a positive significant impact on customers' attitude toward online reviews, therefore, H5 is supported. The results also support H6, suggesting that review volume plays an important role in affecting customers' attitudes toward online reviews. However, source credibility has no effect on consumers' attitudes toward online reviews. Then, H7 is note supported.

We then employed moderated multiple-regression model to test the remaining 6 hypotheses(H8-13), in which we hypothesized that PSR moderates all the causal relationship between the independent variables and the review readers' perceived usefulness of online reviews and their attitudes. To 
Table 1. Validity and reliability analysis

\begin{tabular}{|c|c|c|c|c|}
\hline Variable & Item & Factor loading & CR & AVE \\
\hline \multirow{3}{*}{$\begin{array}{l}\text { Content quality (CQ) } \\
(\mathrm{M}=3.778, \mathrm{SD}=0.670, \alpha=0.877)\end{array}$} & CQ1 & 0.841 & \multirow[t]{3}{*}{0.897} & \multirow[t]{3}{*}{0.744} \\
\hline & CQ2 & 0.854 & & \\
\hline & CQ3 & 0.893 & & \\
\hline \multirow{4}{*}{$\begin{array}{l}\text { Picture quality (PQ) } \\
(\mathrm{M}=3.590, \mathrm{SD}=0.779, \alpha=0.853)\end{array}$} & PQ1 & 0.783 & \multirow[t]{4}{*}{0.875} & \multirow[t]{4}{*}{0.637} \\
\hline & PQ2 & 0.752 & & \\
\hline & PQ5 & 0.839 & & \\
\hline & PQ6 & 0.814 & & \\
\hline \multirow{3}{*}{$\begin{array}{l}\text { Review volume }(\mathrm{RV}) \\
(\mathrm{M}=3.705, \mathrm{SD}=0.699, \alpha=0.756)\end{array}$} & RV2 & 0.874 & \multirow[t]{3}{*}{0.818} & \multirow[t]{3}{*}{0.602} \\
\hline & RV3 & 0.730 & & \\
\hline & RV4 & 0.714 & & \\
\hline \multirow{6}{*}{$\begin{array}{l}\text { Source credibility (SC) } \\
(\mathrm{M}=3.350, \mathrm{SD}=0.756, \alpha=0.913)\end{array}$} & $\mathrm{SC} 1$ & 0.678 & \multirow[t]{6}{*}{0.927} & \multirow[t]{6}{*}{0.684} \\
\hline & $\mathrm{SC} 2$ & 0.795 & & \\
\hline & SC3 & 0.638 & & \\
\hline & $\mathrm{SC} 4$ & 0.970 & & \\
\hline & SC5 & 0.915 & & \\
\hline & SC6 & 0.910 & & \\
\hline \multirow{5}{*}{$\begin{array}{l}\text { Perceived usefulness (PU) } \\
(M=3.882, S D=0.698, \alpha=0.894)\end{array}$} & PU1 & 0.849 & \multirow[t]{5}{*}{0.860} & \multirow[t]{5}{*}{0.556} \\
\hline & PU2 & 0.879 & & \\
\hline & PU3 & 0.590 & & \\
\hline & PU4 & 0.722 & & \\
\hline & PU5 & 0.646 & & \\
\hline \multirow{4}{*}{$\begin{array}{l}\text { Attitude towards online reviews (ATT) } \\
(\mathrm{M}=3.924, \mathrm{SD}=0.735, \alpha=0.905)\end{array}$} & ATT1 & 0.781 & \multirow[t]{4}{*}{0.926} & \multirow[t]{4}{*}{0.759} \\
\hline & ATT2 & 0.890 & & \\
\hline & ATT3 & 0.893 & & \\
\hline & ATT4 & 0.914 & & \\
\hline \multirow{6}{*}{$\begin{array}{l}\text { Perceived social-psychological risk (PSR) } \\
(\mathrm{M}=2.508, \mathrm{SD}=1.165, \alpha=0.962)\end{array}$} & PSR1 & 0.860 & \multirow[t]{6}{*}{0.968} & \multirow[t]{6}{*}{0.834} \\
\hline & PSR2 & 0.893 & & \\
\hline & PSR3 & 0.932 & & \\
\hline & PSR4 & 0.942 & & \\
\hline & PSR5 & 0.933 & & \\
\hline & PSR6 & 0.918 & & \\
\hline
\end{tabular}

examine these hypotheses, we built moderated multiple-regression models. First, the 3 moderating product terms were built by multiplying the value of PSR and the 3 antecedent factors individually. We then added the control variables, antecedent factors, the moderator, and the product terms to the regression model. The significance of the product terms demonstrates the moderating effects of PSR on $\mathrm{CQ}, \mathrm{RV}$ and SC. 
Table 2. Results of discriminant validity analysis

\begin{tabular}{|l|l|l|l|l|l|l|l|}
\hline & CQ & PQ & RV & SC & PU & ATT & PSR \\
\hline CQ & $0.863^{\text {a }}$ & & & & & & \\
\hline PQ & $0.542^{* *}$ & $0.798^{\text {a }}$ & & & & & \\
\hline RV & $0.509^{* *}$ & $0.601^{* *}$ & $0.776^{\mathrm{a}}$ & & & & \\
\hline SC & $0.463^{* *}$ & $0.653^{* *}$ & $0.513^{* *}$ & $0.827^{\mathrm{a}}$ & & & \\
\hline PU & $0.570^{* *}$ & $0.559^{* *}$ & $0.571^{* *}$ & $0.545^{* *}$ & $0.746^{\mathrm{a}}$ & & \\
\hline ATT & $0.566^{* *}$ & $0.503^{* *}$ & $0.479^{* *}$ & $0.417^{* *}$ & $0.735^{* *}$ & $0.871^{\mathrm{a}}$ & \\
\hline PSR & 0.087 & $0.257^{* *}$ & 0.073 & $0.376^{* *}$ & -0.049 & -0.035 & $0.913^{\mathrm{a}}$ \\
\hline
\end{tabular}

Note: ${ }^{a}=$ Square Root of Average Variance Extracted (AVE)

Table 4 and Table 5 show that four of the six hypotheses are significant. Specifically, PSR significantly moderates both RV and SC on PU and ATT. Thus, H9, H10, H12 and H3 are supported. However, PSR has no moderating effect on CQ on PU and ATT, then H8 and H11 are not supported. The results of all analyses are shown in Fig.2.

We also utilized the simple slopes test to explore the internal mechanisms of these moderating effects. This method is helpful for interpreting the interaction effects of two continuous predictors. Following the instructions, we computed, plotted, and tested separate regression lines with one standard deviation below the mean of the moderator and one standard deviation above it. Using this method, we interpreted the significance level of the causal relationships between the independent variable and the dependent variable under high or low levels of the moderator. Fig3-6 show the results of this test, in which the numerical values are the standardized values.

As shown in Fig.3, when PSR is low, the main effect is not significant, likewise, when PSR is high, the main effect of RV is significant, indicating that with an increase in RV, high-PSR online review reader's perceived usefulness is enhanced accordingly. For low-PSR readers, the factor of RV

Table 3. Results of SEM path analysis and summary of hypothesis testing

\begin{tabular}{|l|l|l|l|l|}
\hline \multicolumn{2}{|c|}{ Hypotheses } & \multicolumn{1}{c|}{ Path Coeff. } & \multicolumn{1}{c|}{ t-Value } & \multicolumn{1}{c|}{ Results } \\
\hline H1 & Picture Quality $\rightarrow$ Content Quality & $0.462^{* * *}$ & 12.501 & YES \\
\hline H2 & Content Quality $\rightarrow$ Perceived Usefulness & $0.431^{* * *}$ & 7.021 & YES \\
\hline H3 & Content Quality $\rightarrow$ Attitudes & $0.536^{* * *}$ & 8.401 & YES \\
\hline H4 & Review Volume $\rightarrow$ Perceived Usefulness & $0.295^{* * *}$ & 3.786 & YES \\
\hline H5 & Review Volume $\rightarrow$ Attitudes & $0.228^{* * *}$ & 2.829 & YES \\
\hline H6 & Source Credibility $\rightarrow$ Perceived Usefulness & $0.141^{* *}$ & 3.076 & YES \\
\hline H7 & Source Credibility $\rightarrow$ Attitudes & 0.034 & 0.524 & NO \\
\hline Goodness-of-fit indices & & & 2.823 \\
\hline$\chi^{2} /$ d.f. & & & & 0.851 \\
\hline Goodness-of-fit index (GFI) & & & 0.817 \\
\hline Ajusted GFI (AGFI) & & & 0.922 \\
\hline Comparative fit index (CFI) & & & 0.072 \\
\hline RMSEA
\end{tabular}

Note: ${ }^{*} p<0.05,{ }^{* *} p<0.01,{ }^{* * *} p<0.001$ 
Table 4. Moderating effects of PSR on CQ, RV, SC toward PU

\begin{tabular}{|c|c|c|c|c|c|c|c|}
\hline \multirow[t]{2}{*}{ Hypotheses } & \multirow[t]{2}{*}{ Model } & \multicolumn{2}{|c|}{$\begin{array}{c}\text { Unstandardized } \\
\text { Coefficients }\end{array}$} & \multirow{2}{*}{$\begin{array}{c}\begin{array}{c}\text { Standardized } \\
\text { Coefficients }\end{array} \\
\text { Beta }\end{array}$} & \multirow[t]{2}{*}{$\mathbf{t}$} & \multirow[t]{2}{*}{ Sig. } & \multirow[t]{2}{*}{ Results } \\
\hline & & B & Std. Error & & & & \\
\hline $\mathrm{H} 8$ & inCQPSR & 0.04 & 0.030 & 0.062 & 1.309 & 0.191 & $\mathrm{NO}$ \\
\hline H9 & inRVPSR & 0.07 & 0.030 & 0.105 & 2.268 & 0.024 & YES \\
\hline $\mathrm{H} 10$ & inSCPSR & 0.11 & 0.027 & 0.184 & 4.169 & 0.000 & YES \\
\hline
\end{tabular}

a. Dependent Variable: MPU

Table 5. Moderating effects of PSR on CQ, RV, SC toward ATT

\begin{tabular}{|c|c|c|c|c|c|c|c|}
\hline \multirow[t]{2}{*}{ Hypotheses } & \multirow[b]{2}{*}{ Model } & \multicolumn{2}{|c|}{$\begin{array}{l}\text { Unstandardized } \\
\text { Coefficients }\end{array}$} & \multirow{2}{*}{$\begin{array}{c}\begin{array}{c}\text { Standardized } \\
\text { Coefficients }\end{array} \\
\text { Beta }\end{array}$} & \multirow[b]{2}{*}{$\mathbf{t}$} & \multirow[b]{2}{*}{ Sig. } & \multirow[t]{2}{*}{ Results } \\
\hline & & B & Std. Error & & & & \\
\hline H11 & inCQPSR & 0.03 & 0.033 & 0.042 & 0.879 & 0.380 & $\mathrm{NO}$ \\
\hline H12 & inRVPSR & 0.11 & 0.034 & 0.155 & 3.119 & 0.002 & YES \\
\hline H13 & inSCPSR & 0.13 & 0.032 & 0.191 & 3.849 & 0.000 & YES \\
\hline
\end{tabular}

a. Dependent Variable: ATT

\section{Table 6. Hypothesis assessment}

\begin{tabular}{|c|c|c|c|}
\hline No. & Hypothesis & Sig. & Results \\
\hline $\mathrm{H} 1$ & Picture quality positively influences the review content quality. & $* * *$ & YES \\
\hline $\mathrm{H} 2$ & Content quality positively influences consumer perceived usefulness. & $* * *$ & YES \\
\hline $\mathrm{H} 3$ & Content quality positively influences consumer attitudes. & $* * *$ & YES \\
\hline $\mathrm{H} 4$ & The review volume positively influences consumer perceived usefulness. & $* * *$ & YES \\
\hline H5 & The review volume positively influences consumer attitudes. & $* *$ & YES \\
\hline H6 & Source credibility positively influences consumer perceived usefulness. & $* *$ & YES \\
\hline $\mathrm{H} 7$ & Source credibility positively influences consumer attitudes. & ns & NO \\
\hline $\mathrm{H} 8$ & $\begin{array}{l}\text { The effect of review quality on perceived usefulness will be moderated with the } \\
\text { increase of their perceived social-psychological risk. }\end{array}$ & ns & NO \\
\hline H9 & $\begin{array}{l}\text { The effect of review volume on perceived usefulness will be moderated with the } \\
\text { increase of their perceived social-psychological risk. }\end{array}$ & $*$ & YES \\
\hline H10 & $\begin{array}{l}\text { The effect of source credibility on perceived usefulness will be moderated with the } \\
\text { increase of their perceived social-psychological risk. }\end{array}$ & $* * *$ & YES \\
\hline H11 & $\begin{array}{l}\text { The effect of review quality on attitudes will be moderated with the increase of their } \\
\text { perceived social-psychological risk. }\end{array}$ & $\mathrm{ns}$ & NO \\
\hline H12 & $\begin{array}{l}\text { The effect of review volume on attitudes will be moderated with the increase of their } \\
\text { perceived social-psychological risk. }\end{array}$ & $* *$ & YES \\
\hline H13 & $\begin{array}{l}\text { The effect of source credibility on attitudes will be moderated with the increase of } \\
\text { their perceived social-psychological risk. }\end{array}$ & $* * *$ & YES \\
\hline
\end{tabular}


Figure 2. Results of the research model. Note: ${ }^{*} p<0.05,{ }^{* *} p<0.01,{ }^{* * *} p<0.001$.

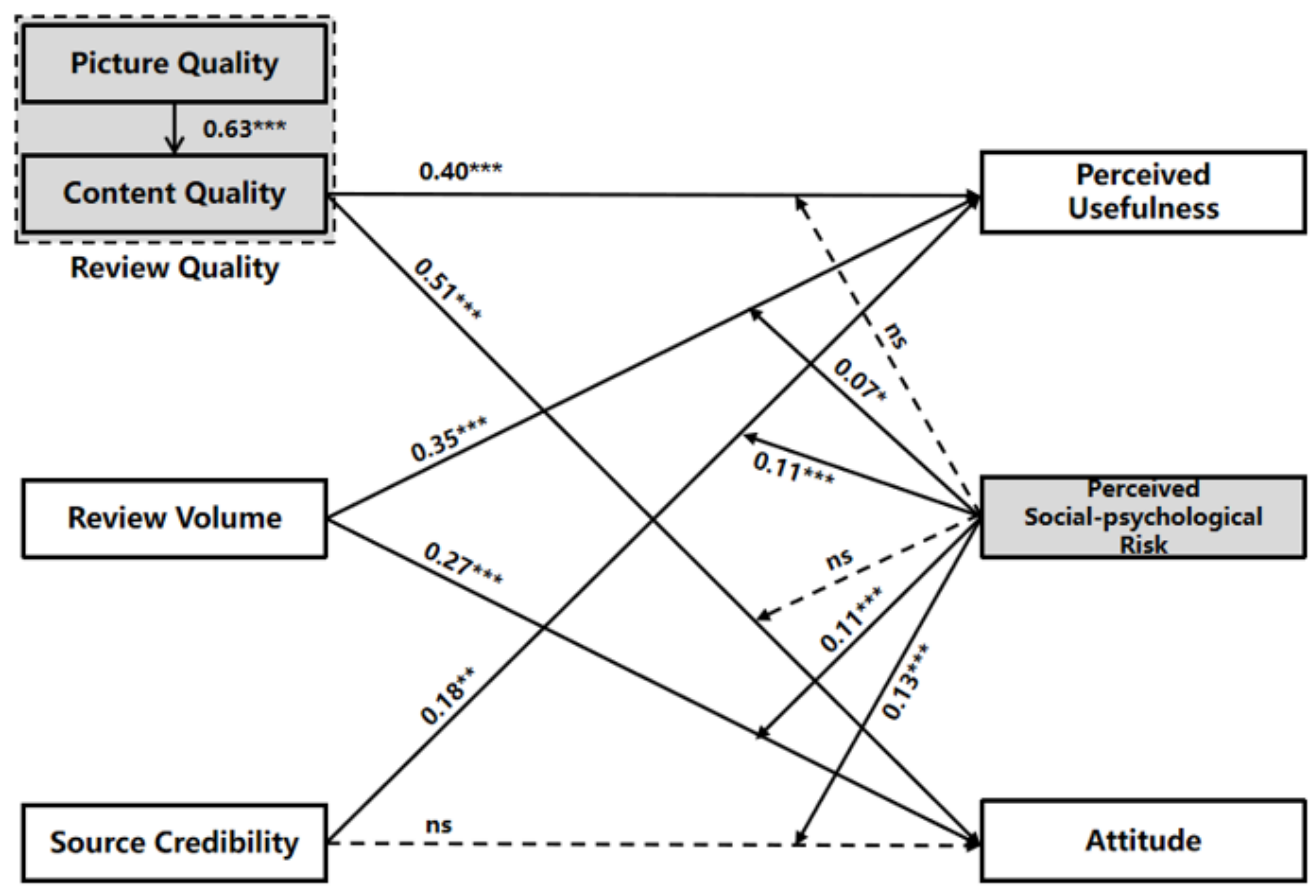

was not that strong enough to affect their perceived usefulness of online reviews. Fig.4, when PSR is high, the slope is steeper than when PSR is low. This also indicates that with an increase in SC, highPSR online review reader's perceived usefulness is enhanced accordingly. For low-PSR readers, the factor of SC was not that strong enough to affect their perceived usefulness of online reviews. Fig.5 shows that with increase in Review volume, the high-PSR readers attitudes toward online reviews is more positive than that of low-PSR readers, i.e. when PSR is high, the main effect of RV is significant, while when PSR is low, the main effect of RV is not significant. Fig.6 shows that with increase in $\mathrm{SC}$, high-PSR readers attitudes toward online reviews is more stronger than that of low-PSR readers.

\section{DISCUSSION}

\subsection{Our Findings}

This study has some practical and interesting findings as follows. Firstly, we found that picture quality has a positive effect on content quality as expected. Secondly, content quality, review volume have positive effects on information perceived usefulness and attitudes, which are consistent with prior studies(Cyr, Head, Lim, \& Stibe, 2018; Filieri et al., 2018; Hussain et al., 2017; Kim et al., 2018; S. Lee \& Choeh, 2018; Luo et al., 2018; Sijoria et al., 2018; S. Teng et al., 2017; Yusuf et al., 2018). Source credibility only influences perceived usefulness, has no effects on attitudes, this finding is partly inconsistent with some studies(Amaro \& Duarte, 2015; Ghosh, 2018; S. Teng et al., 2017). Unlike perceived usefulness, attitudes are not easily influenced by source credibility, because one's attitudes is relatively stable, especially under a context of quick information seeking and assessing process. Another reason why source credibility didn't have significant effects on attitudes, may be that there are both true users' review and merchants' review online, which represents the stance of providers, not the true opinions of true consumers, readers, especially those experienced users, 


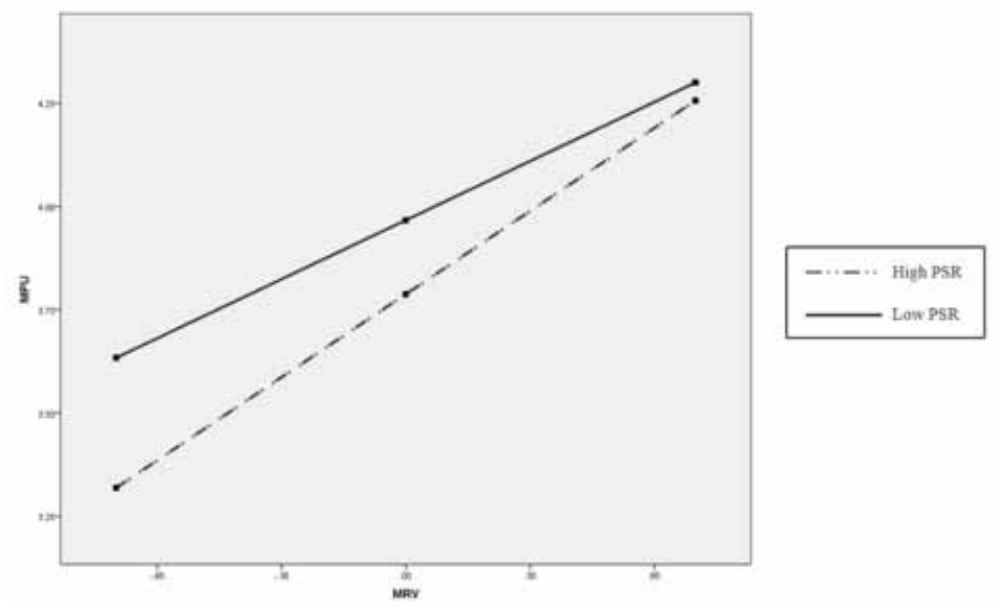

could distinguish them and are unlikely to accept them, because they do not want to be wrong guided, since there are studies confirmed that people do not believe the content of online reviews provided by merchants, such as Hussain et al. (2017) suggest that, compared to the comments from any company expert, the comments of previous consumers are more persuasive on the website. Nevertheless, the strength of those effects is different, both content quality and review volume have a bigger effect on perceived usefulness, meaning that CQ and RV are crucial for readers to assess and evaluate information usefulness, but not SC. As for the properties of receiver, perceived socialpsychological risk moderates both review volume and source credibility on perceived usefulness and attitudes, meaning that review volume and source credibility are considerably sensitive variables easily influenced by consumers' inner social psychological factors. Control variables, age, gender, income, career, education level have no effect on the information perceived usefulness and attitudes. Moreover, although this study targeted to experienced users, we found no significant influence of

Figure 4. The moderating effect of PSR on SC toward PU

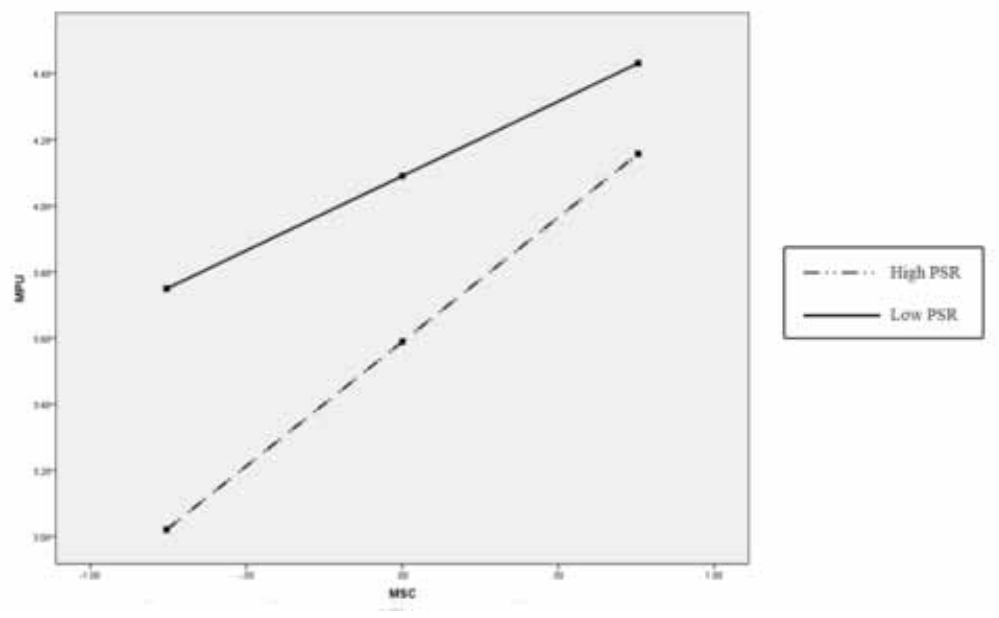




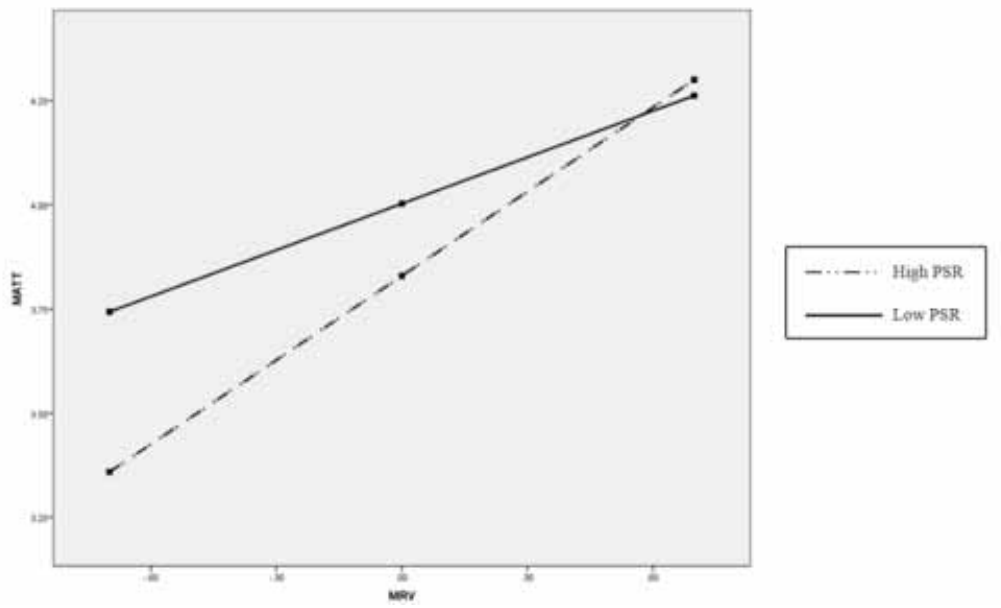

the travel websites use experience and booking times during the past one year, this result indicates that people's past experiences may have other potential effects, at least have no considerable effects in this study, which need to explore in the future.

\subsection{Theoretical Implications}

This study has some contributions to the theoretical advancement. Firstly, as a large body of studies have identified the casual relationship between different online reviews attributes and perceived usefulness, attitudes(Erkan \& Evans, 2016; S. Teng et al., 2017), we choose perceived usefulness and attitudes as two dependent variables instead of behavior intention. What's more, lots of studies also took perceived usefulness and attitudes as mediators or moderators influencing behavior intention(Amaro \& Duarte, 2015; Elwalda et al., 2016; Hussain et al., 2018), in this perspective, perceived usefulness and attitudes are two important variables that bridging consumers' perception of online reviews and their behavior intention, that's to say, only if consumers' perceived usefulness and attributes are

Figure 6. The moderating effect of PSR on SC toward Attitudes

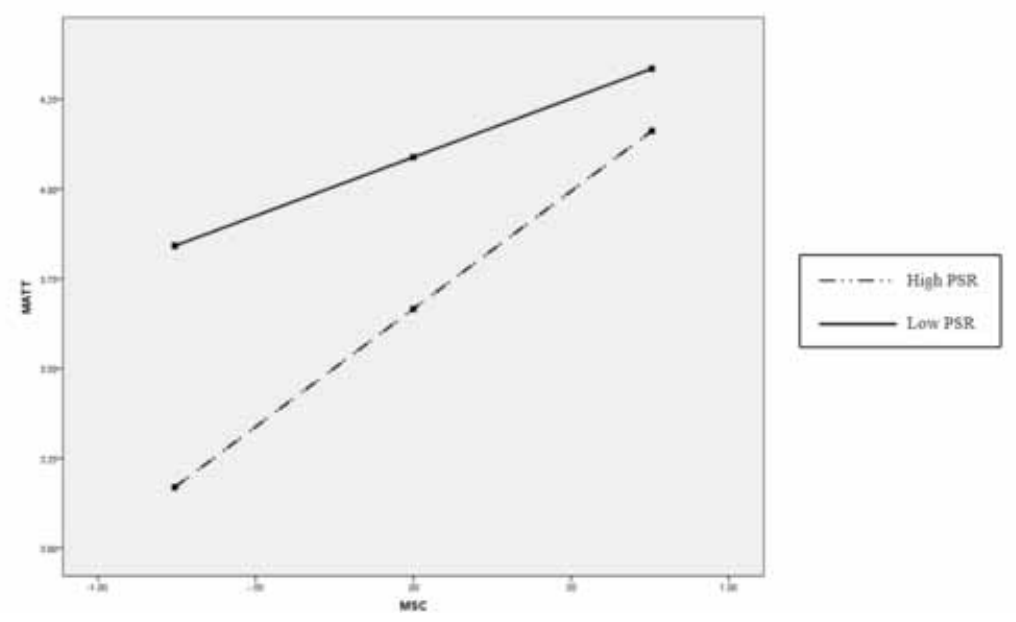


formed, could they make sound purchase decisions. Secondly, targeting to experienced users, who have received little attention in prior studies, we further replicated and confirmed findings of previous studies that content quality, picture quality, review volume and source credibility could significantly influence experienced consumer's perceived usefulness and attitudes, but with exception that source credibility has no effects on attitudes. Thirdly, since there are more and more picture reviews online, to go with the stream, this study divides review quality into content quality and picture quality to validate the effects of picture quality on content quality. Fourthly, as for the moderating effects of perceived social-psychological risk, it moderates the effects of review volume and source credibility toward perceived usefulness and attitudes, unexpectedly, it has no moderating effects on content quality toward perceived usefulness and attitudes. Maybe we could explain this finding from two perspectives, the firs reason may be that content quality is so crucial a reference variable for people to validate the usefulness of online reviews and form their attitudes, that its effects on perceived usefulness and attitudes are not easily influenced by consumers' inherent social-psychological factors. Similarly, review volume represents the popularity of certain travel products and services, so when it is low, which may indicate that the product is not that popular with other people, consumers' perceived social psychological risk may come into play, it easily influences consumers perceived usefulness of online reviews and their attitudes toward them. This finding may also show that as a peripheral cue, could be influenced by social-psychological risks. Fifthly, we could use the prospect theory to explain consumers' shopping travel online. In the context of a planned ad desired travel, when people make their decisions, according to the prospect theory(Tversky, 1979), they don't think rationally, as traditional economics assumes, they act intuitively. Human inertia makes it easier to use intuition rather than logic when dealing with complex problems, this perspective may present some insights on those moderating effects. In a word, people opt to weigh the pros and cons of online reviews, to find a balance between PU and PR before making decision. All those above need to be further investigated in the future.

\subsection{Practical Implications}

This study provides some practical implications for the practitioners as well. The findings of this study demonstrate that online reviews management is of great importance to providers.

Firstly, we found that 4 attributes of online reviews have significant effects on perceived usefulness. As for review quality, this finding give online providers supports for them to encourage people to share high quality reviews, and reward people if they provide true and useful information. For those who are not good at or not interested in writing comments, should encourage them to provide high quality picture reviews, for those who don't like writing comments nor taking pictures, providers should encourage them to share the products or services to their friends; besides the content quality of online reviews, providers should be well aware that users are also concerned about the source credibility. As long as common readers could distinguish the common identity from other members and assess the expertise of the experts(Luo et al., 2018), indicating that source credibility has a significant effect on perceived usefulness, managers should encourage those experienced travelers to give professional opinions, suggestions online. Since results also show that review volume has a significant direct effect on purchase intention, providers should make every endeavor to encourage people to provide reviews online as more as possible, the more reviews are, the more likely people validate the usefulness of the products and form positive attitudes towards it.

Secondly, providers should not only select and provide high quality online travel reviews for users, make practical and valuable travel guides for people to enhance their perceived usefulness and form positive attitudes; meanwhile, since there are positive and negative reviews, providers should learn from online reviews, especially negative online reviews(L. Yan \& Wang, 2018), to identify the problems of people who posted negative reviews, to see whether or not the product or services are consistent with their expectations or they are wrong guided by other people's reviews, or something else. All in all, they should take effective measures to reduce users' perceived risks and uncertainties, 
enhance their perceived usefulness of online reviews. In a word, with new thinking, strategic reflection, paying more attention to online reviews, building an effective comment management system, creating superior value for customer through monitoring and responding to online reviews, providers could effectively enhance customer satisfaction, promote willingness-to-buy and repurchase, and obtain brand competitiveness advantage in the end.

\subsection{Limitations and Future Research}

Several limitations of this study must be acknowledged and suggest further examinations for future research. Firstly, although we use review volume as an important attribute, we did not research how many reviews people always read or make use of, so further research should investigate the quantities of review they read before the make decisions. Secondly, future studies should further explore the effect of picture quality under the central route/systematic processing context. Secondly, besides pictures in online reviews, more and more videos are emerging in online reviews, so does it have effects on consumers' perceived usefulness of online reviews, as well as their attitudes toward related products? This could be an interesting and new topic for researcher to discuss and explore. 


\section{REFERENCES}

Agag, G., \& El-Masry, A. A. (2016). Understanding consumer intention to participate in online travel community and effects on consumer intention to purchase travel online and WOM: An integration of innovation diffusion theory and TAM with trust. Computers in Human Behavior, 60, 97-111. doi:10.1016/j.chb.2016.02.038

Aghakhani, N., Karimi, J., \& Salehan, M. (2018). A Unified Model for the Adoption of Electronic Word of Mouth on Social Network Sites: Facebook as the Exemplar. International Journal of Electronic Commerce, 22(2), 202-231. doi:10.1080/10864415.2018.1441700

Amaro, S., \& Duarte, P. (2015). An integrative model of consumers' intentions to purchase travel online. Tourism Management, 46, 64-79. doi:10.1016/j.tourman.2014.06.006

Arndt, J. (1967). Role Diffusion of Product-Related Conversations in of a New Product. JMR, Journal of Marketing Research, 4. Advance online publication. doi:10.2307/3149462

Baek, H., Ahn, J., \& Choi, Y. (2012). Helpfulness of Online Consumer Reviews: Readers' Objectives and Review Cues. International Journal of Electronic Commerce, 17(2), 99-126. doi:10.2753/JEC1086-4415170204

Bailey, J. E., \& Pearson, S. W. (1983). Development of a tool for measuring and analyzing computer user satisfaction. Management Science, 29(5), 530-545. doi:10.1287/mnsc.29.5.530

Bentler, P. M., \& Bonett, D. G. (1980). Significance tests and goodness of fit in the analysis of covariancestructures. Psychological Bulletin, 88(3), 588-606. doi:10.1037/0033-2909.88.3.588

Blomberg-Nygard, A., \& Anderson, C. K. (2016). United Nations World Tourism Organization Study on Online Guest Reviews and Hotel Classification Systems: An Integrated Approach. Service Science, 8(2), 139-151. doi:10.1287/serv.2016.0139

Book, L. A., Tanford, S., \& Chang, W. (2018). Customer reviews are not always informative: The impact of effortful versus heuristic processing. Journal of Retailing and Consumer Services, 41, 272-280. doi:10.1016/j. jretconser.2018.01.001

Chang, H. H., Fang, P. W., \& Huang, C. H. (2015). The Impact of On-Line Consumer Reviews on Value Perception: The Dual-Process Theory and Uncertainty Reduction. Journal of Organizational and End User Computing, 27(2), 32-57. doi:10.4018/joeuc.2015040102

Chatterjee, P. (2001). Online Reviews: Do Consumers Use Them? Association for Consumer Research.

Chen, C.-C., \& Chang, Y.-C. (2018). What drives purchase intention on Airbnb? Perspectives of consumer reviews, information quality, and media richness. Telematics and Informatics, 35(5), 1512-1523. doi:10.1016/j. tele.2018.03.019

Cheng, X., Fu, S., Sun, J., Bilgihan, A., \& Okumus, F. (2019). An investigation on online reviews in sharing economy driven hospitality platforms: A viewpoint of trust. Tourism Management, 71, 366-377. doi:10.1016/j. tourman.2018.10.020

Cheung, C. M. K., Lee, M. K. O., \& Rabjohn, N. (2008). The impact of electronic word-of-mouth The adoption of online opinions in online customer communities. Internet Research, 18(3), 229-247. doi: $10.1108 / 10662240810883290$

Cheung, M. Y., Luo, C., Sia, C. L., \& Chen, H. (2009). Credibility of Electronic Word-of-Mouth: Informational and Normative Determinants of On-line Consumer Recommendations. International Journal of Electronic Commerce, 13(4), 9-38. doi:10.2753/JEC1086-4415130402

Cyr, D., Head, M., Lim, E., \& Stibe, A. (2018). Using the elaboration likelihood model to examine online persuasion through website design. Information \& Management, 55(7), 807-821. doi:10.1016/j.im.2018.03.009

Dou, X., Walden, J. A., Lee, S., \& Lee, J. Y. (2012). Does source matter? Examining source effects in online product reviews. Computers in Human Behavior, 28(5), 1555-1563. doi:10.1016/j.chb.2012.03.015

Elwalda, A., Lue, K., \& Ali, M. (2016). Perceived derived attributes of online customer reviews. Computers in Human Behavior, 56, 306-319. doi:10.1016/j.chb.2015.11.051 
Erkan, I., \& Evans, C. (2016). The influence of eWOM in social media on consumers' purchase intentions: An extended approach to information adoption. Computers in Human Behavior, 61, 47-55. doi:10.1016/j. chb.2016.03.003

Eslami, S. P., \& Ghasemaghaei, M. (2018). Effects of online review positiveness and review score inconsistency on sales: A comparison by product involvement. Journal of Retailing and Consumer Services, 45, 74-80. doi:10.1016/j.jretconser.2018.08.003

Feathermana, M. S., \& Pavloub, P. A. (2003). Predicting e-services adoption: A perceived risk facets perspective. International Journal of Human-Computer Studies, 59(4), 451-474. doi:10.1016/S1071-5819(03)00111-3

Filieri, R., Hofacker, C. F., \& Alguezaui, S. (2018). What makes information in online consumer reviews diagnostic over time? The role of review relevancy, factuality, currency, source credibility and ranking score. Computers in Human Behavior, 80, 122-131. doi:10.1016/j.chb.2017.10.039

Fornell, C., \& Larcker, D. F. (1981). Evaluating structural equation models with unobservable variables and measurement error. JMR, Journal of Marketing Research, 18(1), 39-50. doi:10.1177/002224378101800104

Furner, C. P., \& Zinko, R. A. (2017). The influence of information overload on the development of trust and purchase intention based on online product reviews in a mobile vs. web environment: An empirical investigation. Electronic Markets, 27(3), 211-224. doi:10.1007/s12525-016-0233-2

Ghosh, T. (2018). Predicting hotel book intention: The influential role of helpfulness and advocacy of online reviews. Journal of Hospitality Marketing \& Management, 27(3), 299-322. doi:10.1080/19368623.2017.1364198

Hair, J. F., Black, W. C., Babin, B. J., \& Anderson, R. E. (2010). Multirative data analysis: A global perspective. Pearson Prentice Hall.

Hansen, T., Jensen, J. M., \& Solgaard, H. S. (2004). Predicting online grocery buying intention: A comparison of the theory of reasoned action and the theory of planned behavior. International Journal of Information Management, 24(6), 539-550. doi:10.1016/j.ijinfomgt.2004.08.004

Huang, Y., Li, C., Wu, J., \& Lin, Z. (2018). Online customer reviews and consumer evaluation: The role of review font. Information \& Management, 55(4), 430-440. doi:10.1016/j.im.2017.10.003

Hur, K., Kim, T. T., Karatepe, O. M., \& Lee, G. (2017). An exploration of the factors influencing social media continuance usage and information sharing intentions among Korean travellers. Tourism Management, 63, 170-178. doi:10.1016/j.tourman.2017.06.013

Hussain, S., Ahmed, W., Jafar, R. M. S., Rabnawaz, A., \& Yang, J. (2017). eWOM source credibility, perceived risk and food product customer's information adoption. Computers in Human Behavior, 66, 96-102. doi:10.1016/j. chb.2016.09.034

Hussain, S., Ahmed, W., Muhammad, R., Jafar, S., Rabnawaz, A., \& Akhtar, H. (2016). Ieee. Electronic Word of Mouth Communications and Consumer's Information Adoption on the Internet.

Hussain, S., Wang, G., Jafar, R. M. S., Ilyas, Z., Mustafa, G., \& Yang, J. (2018). Consumers' online information adoption behavior: Motives and antecedents of electronic word of mouth communications. Computers in Human Behavior, 80, 22-32. doi:10.1016/j.chb.2017.09.019

Kim, S. J., Maslowska, E., \& Malthouse, E. C. (2018). Understanding the effects of different review features on purchase probability. International Journal of Advertising, 37(1), 29-53. doi:10.1080/02650487.2017.1340928

Lee, E.-J., \& Shin, S. Y. (2014). When do consumers buy online product reviews? Effects of review quality, product type, and reviewer's photo. Computers in Human Behavior, 31, 356-366. doi:10.1016/j.chb.2013.10.050

Lee, I. (2018). Usefulness, funniness, and coolness votes of viewers An analysis of social shoppers' online reviews. Industrial Management \& Data Systems, 118(4), 700-713. doi:10.1108/IMDS-04-2017-0151

Lee, S., \& Choeh, J. Y. (2016). The determinants of helpfulness of online reviews. Behaviour \& Information Technology, 35(10), 853-863. doi:10.1080/0144929X.2016.1173099

Lee, S., \& Choeh, J. Y. (2018). The interactive impact of online word-of-mouth and review helpfulness on box office revenue. Management Decision, 56(4), 849-866. doi:10.1108/MD-06-2017-0561 
Litvin, S. W., Goldsmith, R. E., \& Pan, B. (2008). Electronic word-of-mouth in hospitality and tourism management. Tourism Management, 29(3), 458-468. doi:10.1016/j.tourman.2007.05.011

Luo, C., Luo, X., Xu, Y., Warkentin, M., \& Sia, C. L. (2015). Examining the moderating role of sense of membership in online review evaluations. Information \& Management, 52(3), 305-316. doi:10.1016/j. im.2014.12.008

Luo, C., Luo, X. R., \& Bose, R. (2018). Information usefulness in online third party forums. Computers in Human Behavior, 85, 61-73. doi:10.1016/j.chb.2018.02.041

Manganari, E. E., \& Dimara, E. (2017). Enhancing the impact of online hotel reviews through the use of emoticons. Behaviour \& Information Technology, 36(7), 674-686. doi:10.1080/0144929X.2016.1275807

Mitchell, A. A. (1986). The Effect of Verbal and Visual Components of Advertisements on Brand Attitudes and Attitudes Toward the Advertisement. Journal of Consumer Research, 13(1), 12-24. www.jstor.org/stable/2489283

Mitchell, V.-W. (1992). Understanding Consumers' Behaviour: Can Perceived Risk Theory Help? (Vol. 30). Management Decision.

Ohanian, R. (1990). Construction and valildation of a scale to measure celebrity endorsers perceived expertise, trustworthiness, and attractiveness. Journal of Advertising, 19(3), 39-52. doi:10.1080/00913367.1990.10673191

Park, D.-H., Lee, J., \& Han, I. (2007). The effect of on-line consumer reviews on consumer purchasing intention: The moderating role of involvement. International Journal of Electronic Commerce, 11(4), 125-148. doi:10.2753/ JEC1086-4415110405

Park, J., \& Hill, W. T. (2018). Exploring the role of justification and cognitive effort exertion on post-purchase regret in online shopping. Computers in Human Behavior, 83, 235-242. doi:10.1016/j.chb.2018.01.036

Park, M., \& Lennon, S. J. (2009). Brand name and promotion in online shopping contexts. Journal of Fashion Marketing and Management, 13(2), 149-160. doi:10.1108/13612020910957680

Petty, C., \& Cacioppo, J. T. (1984). The effects of involvement on responses to argument quantity and quality:Central and peripheral routes to persuasion. Journal of Personality and Social Psychology, 46(1), 69-81. doi:10.1037/0022-3514.46.1.69

Rich, D. F. C. S. U. (1964). Perceived risk and consumer decision making:The Case of Telephone Shopping. JMR, Journal of Marketing Research, 1, 32-39.

Risselada, H., de Vries, L., \& Verstappen, M. (2018). The impact of social influence on the perceived helpfulness of online consumer reviews. European Journal of Marketing, 52(3/4), 619-636. doi:10.1108/EJM-09-2016-0522

Santosh, T. D., \& Babu, S. K. (2014). Building Trust In Online Reviews by a Customer through Linked Data. IEEE.

Shen, X.-L., Zhang, K. Z. K., \& Zhao, S. J. (2016). Herd behavior in consumers' adoption of online reviews. Journal of the Association for Information Science and Technology, 67(11), 2754-2765. doi:10.1002/asi.23602

Sher, P. J., \& Lee, S.-H. (2009). Consumer skepticism and online reviews: An elaboration likelihood model perspective. Social Behavior and Personality, 37(1), 137-143. doi:10.2224/sbp.2009.37.1.137

Shin, S. Y., Van Der Heide, B., Beyea, D., Dai, Y., \& Prchal, B. (2017). Investigating moderating roles of goals, reviewer similarity, and self-disclosure on the effect of argument quality of online consumer reviews on attitude formation. Computers in Human Behavior, 76, 218-226. doi:10.1016/j.chb.2017.07.024

Sijoria, C., Mukherjee, S., \& Datta, B. (2018). Impact of the antecedents of eWOM on CBBE. Marketing Intelligence \& Planning, 36(5), 528-542. doi:10.1108/MIP-10-2017-0221

Smith., E. R., \& DeCoster, J. (2000). Dual-Process Models in Social and Cognitive Psychology: Conceptual Integration and Links to Underlying Memory Systems (Vol. 4). Personality and Social Psychology Review.

Taylor, J. W. (1974). The Role of Risk in Consumer Behavior. Journal of Marketing, 38, 54-60.

Teng, C.-C., Lu, A. C. C., \& Huang, T.-T. (2018). Drivers of consumers' behavioral intention toward green hotels. International Journal of Contemporary Hospitality Management, 30(2), 1134-1151. doi:10.1108/ IJCHM-04-2017-0203 
Teng, S., Khong, K. W., Chong, A. Y.-L., \& Lin, B. (2017). Examining the Impacts of Electronic Word-ofMouth Message on Consumers' Attitude. Journal of Computer Information Systems, 57(3), 238-251. doi:10.1 080/08874417.2016.1184012

Tversky, D. K. A. (1979). An Analysis of Decision under Risk (Vol. 47). Econometrica.

Westbrook, R. A. (1987). Product/Consumption-B and Affective Postpurchase Processes. Journal of Marketing Research, 24.

Wu, Y., Ngai, E. W., Wu, P., \& Wu, C. (2020). Fake online reviews: Literature review, synthesis, and directions for future research. Decision Support Systems, 132, 113280. doi:10.1016/j.dss.2020.113280

Yan, L., \& Wang, X. (2018). Why posters contribute different content in their positive online reviews: A social information-processing perspective. Computers in Human Behavior, 82, 199-216. doi:10.1016/j.chb.2018.01.009

Yan, X., Wang, J., \& Chau, M. (2015). Customer revisit intention to restaurants: Evidence from online reviews. Information Systems Frontiers, 17(3), 645-657. doi:10.1007/s10796-013-9446-5

Yusuf, A. S., Hussin, A. R. C., \& Busalim, A. H. (2018). Influence of e-WOM engagement on consumer purchase intention in social commerce. Journal of Services Marketing, 32(4), 493-504. doi:10.1108/JSM-01-2017-0031

Zhang, K. Z. K., Zhao, S. J., Cheung, C. M. K., \& Lee, M. K. O. (2014). Examining the influence of online reviews on consumers' decision-making: A heuristic-systematic model. Decision Support Systems, 67, 78-89. doi:10.1016/j.dss.2014.08.005

\section{ENDNOTES}

Bai Haiqing in the Xiamen University, School of Journalism and Communication, Xiamen University, Xiamen 361005,China, who is the Corresponding Author,

Lu Jinting 1, Bai Haiqing 2*

1,2 Xiamen University, School of Journalism and Communication, Xiamen University, Xiamen 361005,

China 


\section{APPENDIX A}

\section{Table 7. Construct indicators}

\begin{tabular}{|c|c|c|}
\hline & Construct and Items Description & References \\
\hline CQ1 & The content of these reviews is factual. & \multirow{3}{*}{$\begin{array}{l}\text { Adapted from Luo et al. (2015) and M. Y. } \\
\text { Cheung, Luo, Sia, and Chen (2009), Dou, } \\
\text { Walden, Lee, and Lee (2012), and Chatterjee } \\
\text { (2001) }\end{array}$} \\
\hline CQ2 & The content of these reviews is credible & \\
\hline CQ3 & The content of these reviews is objective. & \\
\hline PQ1 & Online reviews' pictures are clear. & Adapted from Bailey and Pearson (1983) \\
\hline PQ2 & There are lots of pictures in online reviews. & Adapted from Bailey and Pearson (1983) \\
\hline PQ3 & Pictures are aesthetic. & New measure \\
\hline PQ4 & The pictures in the reviews make readers the travel look appealing. & Adapted from Cyr et al. (2018) \\
\hline RV1 & There are both positive and negative reviews. & Luo et al. (2015) \\
\hline RV2 & The quantity of review information is large. & D.-H. Park et al. (2007) \\
\hline RV3 & Many people had posted online reviews about the products. & Adapted from Zhang et al. (2014) \\
\hline $\mathrm{SC} 1$ & People who posted these reviews are early users of the websites. & New measure \\
\hline $\mathrm{SC} 2$ & Thinking back to the reviewers, I think they are experienced. & Adapted from Dou et al. (2012) \\
\hline $\mathrm{SC} 3$ & Thinking back to the reviewers, I think they are reliable. & Adapted from Dou et al. (2012) \\
\hline $\mathrm{SC} 4$ & Thinking back to the reviewers, I think they are experts on the products. & $\begin{array}{l}\text { Zhang et al. (2014), and Shen et al. (2016), } \\
\text { Dou et al. (2012) }\end{array}$ \\
\hline SC5 & $\begin{array}{l}\text { Thinking back to the online reviewers, I think they are skilled at shopping } \\
\text { travel online. }\end{array}$ & $\begin{array}{l}\text { Adapted from Dou et al. (2012), Dou et al. } \\
\text { (2012) }\end{array}$ \\
\hline SC6 & $\begin{array}{l}\text { Thinking back to the reviewers, I think they are knowledgeable on the } \\
\text { products. }\end{array}$ & Zhang et al. (2014), and (Shen et al., 2016)v \\
\hline PU1 & Reviews increase my effectiveness when shopping travel online. & $\begin{array}{l}\text { Adapted from Amaro and Duarte (2015), and } \\
\text { Elwalda et al. (2016) }\end{array}$ \\
\hline PU2 & Reviews are helpful for decision making when shopping travel online. & Adapted from Erkan and Evans (2016) \\
\hline PU3 & Reviews have improved my judgment. & Adapted from Agag and El-Masry (2016) \\
\hline PU4 & Reviews is helpful for me to understand the product comprehensively. & Adapted from D.-H. Park et al. (2007) \\
\hline PU5 & Review information is useful/helpful to my life. & Adapted from D.-H. Park et al. (2007) \\
\hline ATT1 & I think reading reviews before shopping travel online is a good idea. & \multirow{4}{*}{$\begin{array}{l}\text { Adapted from Amaro and Duarte (2015), and } \\
\text { D.-H. Park et al. (2007) }\end{array}$} \\
\hline ATT2 & I think it is wise to read reviews before shopping travel online. & \\
\hline ATT3 & I think it is pleasant to read reviews before shopping travel online. & \\
\hline ATT4 & $\begin{array}{l}\text { If I do not read the reviews presented on the Web site when I buy a product } \\
\text { on-line, I worry about my decision. }\end{array}$ & \\
\hline PSR1 & Shopping travel online doesn't fit in well with my self-image or self-concept. & \multirow{6}{*}{$\begin{array}{l}\text { Adapted from Feathermana. and Pavloub. } \\
\text { (2003) }\end{array}$} \\
\hline PSR2 & Shopping travel online doesn't satisfy me. & \\
\hline PSR3 & Shopping travel online make me regret. & \\
\hline PSR4 & Shopping travel online negatively affect the way others think of me. & \\
\hline PSR5 & Shopping travel online may affect my social relationships. & \\
\hline PSR6 & Others may think it unwise for me to shop travel online. & \\
\hline
\end{tabular}




\section{APPENDIX B}

Table 8. Respondents' demographic profile and review use experience ( $\mathrm{N}=355)$

\begin{tabular}{|c|c|c|c|}
\hline & & Frenquency(N) & Column N \% \\
\hline \multirow{2}{*}{ Gender } & Male & 165 & $46.50 \%$ \\
\hline & Female & 190 & $53.50 \%$ \\
\hline \multirow{4}{*}{ Age } & $19-25$ & 111 & $31.30 \%$ \\
\hline & $26-35$ & 142 & $40.00 \%$ \\
\hline & $36-45$ & 85 & $23.90 \%$ \\
\hline & $46+$ & 17 & $4.80 \%$ \\
\hline \multirow{5}{*}{ Monthly income(RMB) } & $\leq 1000$ & 30 & $8.50 \%$ \\
\hline & $1001-3000$ & 75 & $21.10 \%$ \\
\hline & $3001-5000$ & 49 & $13.80 \%$ \\
\hline & $5001-8000$ & 84 & $23.70 \%$ \\
\hline & $\geq 8001$ & 117 & $33.00 \%$ \\
\hline \multirow{5}{*}{ Education } & Primary School & 2 & $0.60 \%$ \\
\hline & High School & 3 & $0.80 \%$ \\
\hline & Bachelor degree & 191 & $53.80 \%$ \\
\hline & Mster degree & 124 & $34.90 \%$ \\
\hline & Doctoral degree & 35 & $9.90 \%$ \\
\hline \multirow{7}{*}{ Occupation } & Student & 107 & $30.10 \%$ \\
\hline & Company employer & 103 & $29.00 \%$ \\
\hline & $\begin{array}{l}\text { Individual household/Self- } \\
\text { employed }\end{array}$ & 21 & $5.90 \%$ \\
\hline & Civil servant & 97 & $27.30 \%$ \\
\hline & Sales/Services & 9 & $2.50 \%$ \\
\hline & Retried & 1 & $0.30 \%$ \\
\hline & Other & 17 & $4.80 \%$ \\
\hline \multirow{4}{*}{$\begin{array}{l}\text { How often did you buy travel products during } \\
\text { the past year? }\end{array}$} & 1times & 115 & $32.40 \%$ \\
\hline & 2times & 91 & $25.60 \%$ \\
\hline & 3times & 59 & $16.60 \%$ \\
\hline & $\geq 4$ times & 90 & $25.40 \%$ \\
\hline \multirow{4}{*}{ How long have you used this website? } & Less than one year & 55 & $15.50 \%$ \\
\hline & $1-3$ years & 147 & $41.40 \%$ \\
\hline & 3 -5years & 83 & $23.40 \%$ \\
\hline & More than 5 years & 70 & $19.70 \%$ \\
\hline \multirow{2}{*}{ Read reviews/comments before purchase } & Yes & 355 & $100.00 \%$ \\
\hline & No & 0 & $0.00 \%$ \\
\hline
\end{tabular}

